\title{
Adaptabilidade e estabilidade fenotípica de genótipos de cana-de-açúcar no estado de Minas Gerais
}

\author{
Adaptability and phenotypic stability of sugarcane genotypes in the state of Minas Gerais \\ Luís Cláudio Inácio da Silveira ${ }^{\mathrm{I}}$ Volmir Kist ${ }^{\mathrm{II}}$ Thiago Otávio Mendes de PaulaII

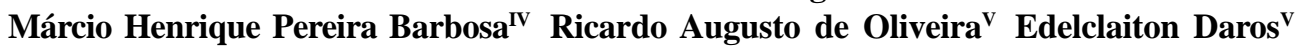

\section{RESUMO}

O objetivo deste trabalho foi avaliar a adaptabilidade e estabilidade fenotípica de genótipos de canade-açúcar no estado de Minas Gerais. Foram avaliados 15 genótipos em nove ambientes. Os experimentos foram conduzidos em blocos completos casualizados, com três repetições. Para discriminar os genótipos, utilizou-se a variável TPH (toneladas de pol por hectare). Os valores corresponderam à média de dois cortes. Os resultados revelaram que a cultivar testemunha RB867515 apresentou maior adaptabilidade geral e estabilidade fenotípica, seguida pelo genótipo RB987935, que apresentou a maior média e elevada adaptabilidade geral e específica para ambientes favoráveis e desfavoráveis, podendo ser indicada para cultivo comercial.

Palavras-chave: Saccharum, interação genótipo x ambiente, estatísticas não paramétricas.

\section{ABSTRACT}

The objective of this research was to evaluate the adaptability and phenotypic stability of genotypes of sugarcane in the state of Minas Gerais, Brazil. There had been evaluated 15 genotypes in nine environments. The experiments were conducted in a randomized block design with three replications. To discriminate the genotypes the variable TPH (tons of pol per hectare) was used. These values corresponded to the average of two cuts. The results showed that the check RB867515 presented greater general adaptability and phenotypic stability, followed by genotype RB987935, which had the highest average and high general and specific adaptability to favorable and unfavorable environments that may be suitable for commercial cultivation.

Key words: Saccharum, genotype-environment interaction, non-parametric statistics.

\section{INTRODUCÃO}

O cultivo da cana-de-açúcar (Saccharum spp) vem crescendo significativamente nos últimos anos no Brasil. Na safra 2010/11, foram cultivados cerca de 8 milhões de hectares no país, a partir dos quais foram produzidas 624.991.000t de cana-de-açúcar, o que correspondeu a uma produtividade média de $77,8 \mathrm{tha}^{-1}$ (CONAB 2011). Em relação à safra anterior, esses valores correspondem a aumentos de 8,4\% na área cultivada e de $3,4 \%$ na produção. Junto à expansão da cultura, aumenta a exigência por cultivares altamente responsivas, tanto em produção de cana-de-açúcar quanto em concentração de açúcar, para o cultivo em ambientes diversos.

Entretanto, em sua grande maioria, os genótipos apresentam comportamentos diferenciados em relação aos distintos ambientes de cultivo. Por conta disso, é fundamental a identificação de genótipos de

\footnotetext{
'Programa de Pós-graduação em Fitotecnia e Fitossanitarismo, Universidade Federal do Paraná (UFPR), Curitiba, PR, Brasil.

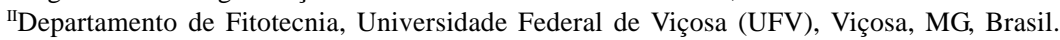

IIIPrograma de Pós-graduação em Melhoramento e Genética, UFV, Viçosa, MG, Brasil.

Iv Departamento de Fitotecnia, UFV, 36570-000, Viçosa, MG, Brasil. E-mail: marciobarbosaufv@gmail.com. Autor para correspondência.

vDepartamento de Fitotecnia e Fitossanitarismo, UFPR, Curitiba, PR, Brasil.
} 
comportamento previsível e responsivos às variações ambientais para condições amplas ou específicas de cultivo (CRUZ et al., 2004).

Na literatura, diversas metodologias são encontradas para a análise da adaptabilidade e estabilidade fenotípica. Por sua vez, essas estatísticas são complementares à análise de variância conjunta que é conduzida a partir de dados experimentais obtidos de diversos ambientes (CRUZ et al., 2004). Entre as metodologias mais comuns, encontram-se as análises regressão linear, regressão não linear, análises multivariadas e estatísticas não paramétricas. Apesar das diversas opções, muitas vezes, são preferidas pelos pesquisadores àquelas metodologias que permitem fácil interpretação dos resultados e que, ao mesmo tempo, tornam possível a identificação dos genótipos superiores com os respectivos graus de adaptabilidade e estabilidade fenotípica (MURAKAMI et al., 2004; BARROS etal., 2008; NASCIMENTOFILHO etal., 2009).

Nesse sentido, destaca-se a metodologia de LIN \& BINNS (1988), que é uma estatística não paramétrica, em que o parâmetro $\mathrm{P}_{\mathrm{i}}$ é adotado como medida de estabilidade fenotípica. Esse parâmetro corresponde ao somatório dos quadrados médios das distâncias entre a resposta de um determinado genótipo num dado ambiente e a resposta do genótipo superior no mesmo ambiente, em todos os ambientes avaliados. Dessa forma, quanto menor o valor de $\mathrm{P}_{\mathrm{i}}$, menor é o desvio em torno da produtividade máxima, por consequência, maior é a adaptabilidade geral e estabilidade fenotípica do genótipo (FARIAS et al., 1997; DAHER et al., 2003; BOTREL et al., 2005).

No entanto, a proposta de LIN \& BINNS (1988) não distingue os genótipos quanto à adaptação específica. Diante disso, CARNEIRO (1998) sugeriu a decomposição do estimador $\mathrm{P}_{\mathrm{i}}$ de LIN \& BINNS (1988) em ambientes favoráveis $\left(\mathrm{P}_{\mathrm{if}}\right)$ e desfavoráveis $\left(\mathrm{P}_{\mathrm{id}}\right)$. Nesse caso, a classificação dos ambientes em favorável ou desfavorável é feita com base nos índices ambientais, os quais são obtidos a partir da diferença dos genótipos em cada ambiente e a média geral do experimento. Assim, é possível identificar os genótipos de melhor performance geral e alocá-los nos ambientes específicos, favoráveis ou desfavoráveis, de acordo com as condições edafoclimáticas, de manejo e tecnologia utilizada pelos produtores.

O objetivo deste trabalho foi avaliar a adaptabilidade e estabilidade fenotípica de genótipos de cana-de-açúcar no estado de Minas Gerais pelas metodologias não paramétricas de LIN \& BINNS (1988) e a modificada por CARNEIRO (1998).

\section{MATERIAL E MÉTODOS}

Nas safras agrícolas de 2004/05 e 2005/06 foram avaliados 15 genótipos de cana-de-açúcar, sendo duas testemunhas (RB867515 e RB72454) e 13 clones $\mathrm{RB}$, em nove unidades produtoras no Estado de Minas Gerais (Tabela 1). Os experimentos faziam parte da fase final de avaliação de clones do Programa de Melhoramento Genético da Cana-de-açúcar da Universidade Federal de Viçosa, o qual é vinculado à Rede Interuniversitária para o Desenvolvimento do Setor Sucroalcooleiro (PMGCA/UFV/RIDESA).

Os experimentos foram conduzidos em blocos completos casualizados, com três repetições. As parcelas foram constituídas por quatro linhas de $10 \mathrm{~m}$, com espaçamento de $1,40 \mathrm{~m}$ entre linhas. A implantação dos experimentos foi realizada entre fevereiro e março de 2004, com a distribuição de 18 gemas por metro linear.

O primeiro corte da cana-de-açúcar foi feito 18 meses após o plantio (cana planta) e o segundo, 12 meses após o primeiro (cana soca). A colheita dos colmos foi feita com despalha prévia a fogo. A pesagem foi realizada com o auxílio de uma carregadora, acoplando-se à garra desta um dinamômetro. De posse dos pesos dos colmos para cada parcela (kg), estimouse a produtividade de colmos, dada em TCH (toneladas de colmos por hectare). O teor de pol (POL) na canade-açúcar foi obtido a partir da análise tecnológica de 10 colmos de cada parcela. Assim, a variável produtividade de pol, dada em TPH (toneladas de pol por hectare) foi obtida por meio do estimador: $\mathrm{TPH}=(\mathrm{TCH} \times \mathrm{POL}) / 100$.

Para discriminar os genótipos, os valores médios obtidos da variável TPH a partir da cana planta e cana soca foram submetidos às análises. Inicialmente, os dados foram submetidos a análises de variâncias individuas por ambiente. Na sequência, foi conduzida a análise de variância conjunta, considerando o efeito de genótipo como fixo e o de ambiente como aleatório, conforme o seguinte modelo: $Y_{i j k}=m+B /$ $A_{j k}+G_{i}+A_{j}+G A_{i j}+E_{i j k}$, em que: $Y_{i j k}$ : representa o i-ésimo genótipo no j-ésimo ambiente e no k-ésimo bloco; m: é a média geral; $\mathrm{B} / \mathrm{A}_{\mathrm{jk}}$ : corresponde ao bloco dentro de ambiente no j-ésimo ambiente e no k-ésimo bloco; $\mathrm{G}_{\mathrm{i}}$ : é o efeito do i-ésimo genótipo; $A_{j}$ : é o efeito do j-ésimo ambiente; $\mathrm{GA}_{\mathrm{ij}}$ : é o efeito da interação do i-ésimo genótipo com o j-ésimo ambiente; e $\mathrm{E}_{\mathrm{ijk}}$ : é o efeito do erro experimental.

A homogeneidade das variâncias residuais foi verificada por meio da razão entre o maior e o menor quadrado médio de resíduo (QMR), considerando o valor sete como limite para a validação da análise, conforme descrito em CRUZ et al. (2004). 
Adaptabilidade e estabilidade fenotípica de genótipos de cana-de-açúcar no estado de Minas Gerais.

Tabela 1 - Localização dos ambientes onde foram conduzidos os nove experimentos com 15 genótipos de cana-de-açúcar, em Minas Gerais, nas safras agrícolas 2004/05 e 2005/06.

\begin{tabular}{|c|c|c|c|c|c|}
\hline Ambientes & Municípios (MG) & Usinas $^{(a)}$ & Latitude (S) & Longitude (W) & Altitude (m) \\
\hline A1 & João Pinheiro & DWD & $17^{\circ} 44^{\prime} 33^{\prime \prime}$ & $46^{\circ} 10^{\prime} 21^{\prime \prime}$ & 1000 \\
\hline $\mathrm{A} 2$ & Campo Florido & CAN & $19^{\circ} 45^{\prime} 38^{\prime \prime}$ & $48^{\circ} 34^{\prime} 20^{\prime \prime}$ & 642 \\
\hline A3 & Conceição das Alagoas & USA & $19^{\circ} 54^{\prime} 53^{\prime \prime}$ & $48^{\circ} 23^{\prime} 18^{\prime \prime}$ & 509 \\
\hline A4 & Araporã & UAV & $18^{\circ} 26^{\prime} 10^{\prime \prime}$ & $49^{\circ} 11^{\prime} 06^{\prime \prime}$ & 461 \\
\hline A5 & Guaranésia & $\mathrm{DAB}$ & $21^{\circ} 17^{\prime} 57^{\prime \prime}$ & $46^{\circ} 48^{\prime} 09^{\prime \prime}$ & 751 \\
\hline A6 & Canápolis & UTR & $18^{\circ} 43^{\prime} 30^{\prime \prime}$ & $49^{\circ} 12^{\prime} 16^{\prime \prime}$ & 662 \\
\hline A7 & Monte Alegre & UMA & $18^{\circ} 52^{\prime} 14^{\prime \prime}$ & $48^{\circ} 52^{\prime} 51^{\prime \prime}$ & 730 \\
\hline A8 & Pompéu & AGR & $19^{\circ} 13^{\prime} 28^{\prime \prime}$ & $44^{\circ} 06^{\prime} 07^{\prime \prime}$ & 657 \\
\hline A9 & Passos & UAP & $20^{\circ} 43^{\prime} 08^{\prime \prime}$ & $46^{\circ} 36^{\prime} 35^{\prime \prime}$ & 745 \\
\hline
\end{tabular}

(a)DWD: Destilaria DW, CAN: Associação dos produtores de cana de Campo Florido, USA: Usina Santo Ângelo, UAV: Usina Alvorada, DAB: Destilaria Alvorada Bebedouro, UTR: Usina Triálcool, UMA: Usina Monte Alegre, AGR: Destilaria Agropéu, UAP: Usina Açucareira Passos.

Depois de constatado o efeito significativo da interação $\mathrm{G}$ x A pelo teste $\mathrm{F}$ da análise de variância conjunta, procedeu-se à análise de adaptabilidade e estabilidade fenotípica pela metodologia de Lin \& Binns (1988), conforme o seguinte estimador: $P_{i}=\sum_{i=1}^{n}\left(X_{i j}-M_{j}\right)^{2} / 2 n$, em que: $\mathrm{P}_{\mathrm{i}}$ é a estimativa da adaptabilidade e estabilidade do genótipo $\mathrm{i} ; \mathrm{X}_{\mathrm{ij}}$ é a produtividade do i-ésimo genótipo no j-ésimo ambiente; $\mathrm{M}_{\mathrm{j}}$ é a reposta máxima observada entre todos os genótipos no ambiente j; e n é o número de ambientes.

A estimativa $\mathrm{P}_{\mathrm{i}}$ foi decomposta conforme proposto por CARNEIRO (1998), na qual, na expressão do $\mathrm{P}_{\mathrm{i}}$, o $n$ foi substituído por $f$ e $d$, que correspondem ao número de ambientes favoráveis e desfavoráveis, respectivamente. Desse modo, estimativas foram conduzidas por meio das seguintes expressões: $P_{i f}=\sum_{j=1}^{n}\left(X_{i j}-M_{j}\right)^{2} / 2 f$ e, $P_{i d}=\sum_{j=1}^{n}\left(X_{i j}-M_{j}\right)^{2} / 2 d$ respectivamente, conforme descrito em CRUZ \& CARNEIRO (2006). Todas as análises foram realizadas com o auxílio do programa estatístico GENES (CRUZ, 2006).

\section{RESULTADOS E DISCUSSÃO}

Diferenças significativas $(\mathrm{P}<0,05)$ entre genótipos foram reveladas pelas análises de variâncias individuais em todos os ambientes, exceto em A8 (Tabela 2). Mesmo assim, esse resultado revela que existe variabilidade genética entre os genótipos envolvidos nesse estudo, o que é fundamental para a sequência do processo de seleção de genótipos superiores.

A análise de variância conjunta revelou diferenças altamente significativas $(\mathrm{P}<0,01)$ para as fontes de variação de ambientes (A), genótipos (G) e interação GxA (Tabela 2). O efeito significativo da interação GxA revelou que os genótipos apresentaram performance diferenciada nos diversos ambientes de avaliação, o que justifica a condução de análises de adaptabilidade e estabilidade fenotípica. Deve ser destacado que a análise de variância conjunta foi validada pelo coeficiente obtido entre o maior e menor quadrado médio residual (QMR), o qual foi de 2,9. Segundo CRUZ et al. (2004), quando esse valor for de magnitude inferior a sete, a análise pode ser validada, o que está de acordo com o procedimento adotado neste estudo.

A média geral do experimento para a variável TPH foi de 18,2t ha-1 , o que é um valor de magnitude relativamente elevado. Mesmo assim, a média geral do experimento não foi maior porque as médias obtidas nos ambientes A4, A7 e A8 foram relativamente baixas (Tabela 2). O fraco desempenho dos genótipos nesses ambientes pode ser explicado com base nas condições edafoclimáticas. O ambiente A4 caracterizou-se por apresentar boa fertilidade natural do solo, no entanto, a elevada temperatura média anual e a baixa e mal distribuída precipitação pluviométrica têm limitando a obtenção de melhores índices de rendimento nesse ambiente. No ambiente A7, a precipitação pluviométrica ocorreu de forma regular e em quantidade suficiente para o bom desenvolvimento da cultura que, segundo DIOLA \& SANTOS (2010), necessita de maiores concentrações na fase vegetativa e menores na fase de maturação. No entanto, nesse ambiente, a fertilidade natural do solo é baixa. Esse fator associado a temperaturas mais baixas durante o ano todo constituíram as principais limitações para melhor performance dos genótipos. Além do mais, a combinação desses fatores foi favorável ao surgimento 
Tabela 2 - Quadrados médios das análises de variâncias individuais, resumo da análise de variância conjunta, médias, coeficientes de variação $(\mathrm{CV})$ e coeficiente de relação entre o maior e menor QMR para a variável TPH de 15 genótipos avaliados em nove ambientes, em Minas Gerais, nas safras 2005 e 2006.

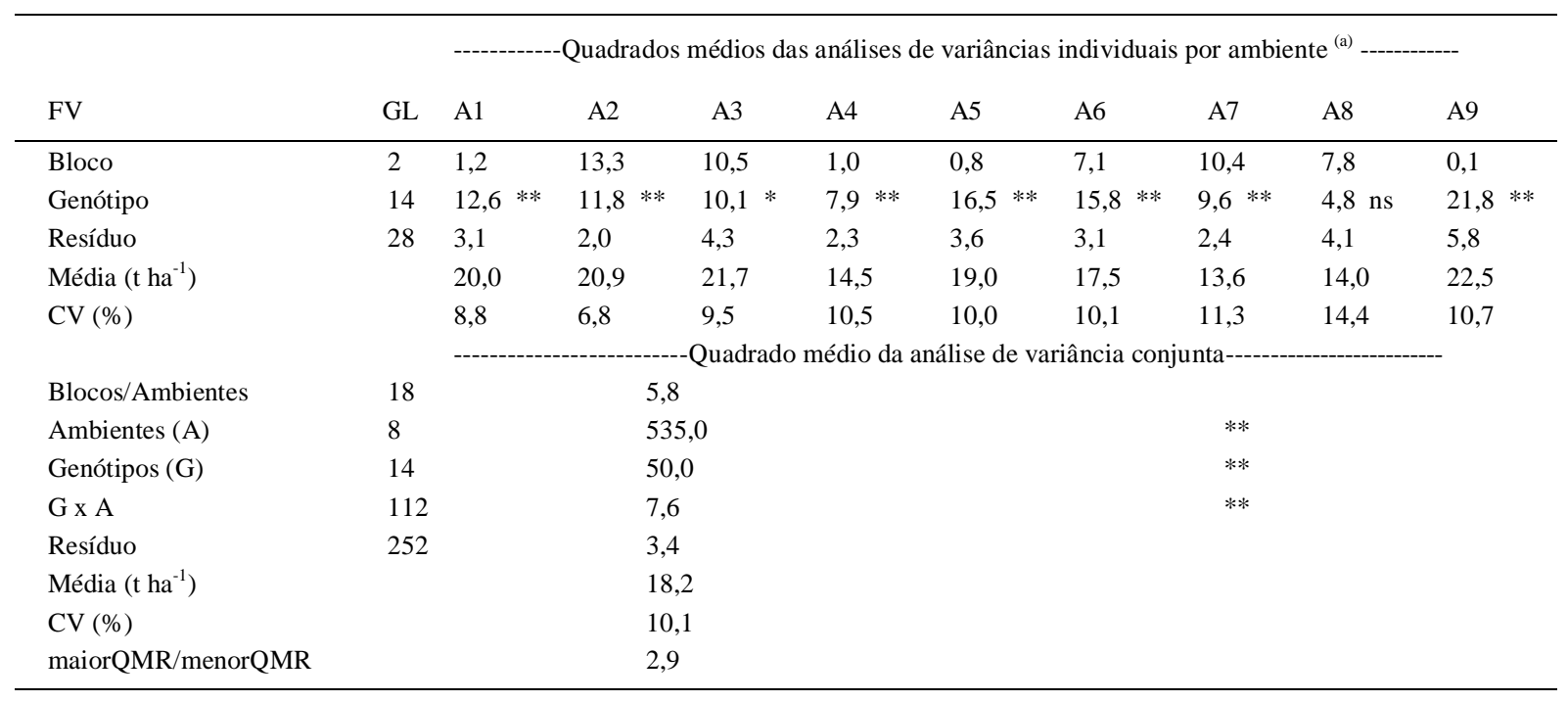

(a)A1: João Pinheiro (DWD), A2: Campo Florido (CAN), A3: Conceição das Alagoas (USA), A4: Araporã (UAV), A5: Guaranésia (DAB), A6: Canápolis (UTR), A7: Monte Alegre (UMA), A8: Pompéu (AGR), A9: Passos (UAP). ns, *,**: correspondem a não significativo, significativo a $5 \%$ e $1 \%$ de probabilidade de erro, respectivamente, pelo teste $\mathrm{F}$.

de algumas doenças, com maior destaque para ferrugem marrom (Puccinia melanocephala). Por último, no ambiente A8, as piores condições edafoclimáticas para o cultivo da cana-de-açúcar foram encontradas. Isto é, baixa fertilidade natural do solo, baixa capacidade de retenção d’água e, baixa e mal distribuída precipitação pluviométrica. Apesar dessas considerações, médias bem inferiores à obtida no presente estudo, também envolvendo clones RB, foram relatadas por LAVORENTI \& MATSUOKA(2001) em São Paulo, ZENI NETO et al. (2008) e GUERRA et al. (2009) no Paraná.

Os coeficientes de variação experimental (CV) variaram de 6 a 10\%, considerando as análises de variâncias individuais e conjunta (Tabela 2). De acordo com a classificação de GOMES (2000), esses valores conferem uma boa precisão experimental, e, portanto, boa confiabilidade às informações extraídas dessas análises.

Pela metodologia de LIN \& BINNS (1988), identificou-se a testemunha RB867515 como genótipo de maior adaptabilidade geral e estabilidade fenotípica (menor $\mathrm{P}_{\mathrm{i} \text { geral }}$ ) nos nove ambientes, seguido pelo genótipo RB987935 (Tabela 3). Esse dois genótipos também foram os que menos contribuíram para a interação GxA (dados não mostrados). Na sequência, com valores de $\mathrm{P}_{\mathrm{i} \text { geral }}$ maiores, porém relativamente similares entre si, apareceram os genótipos RB935641, RB925211 e RB935686, nessa ordem, respectivamente
(Tabela 3). Apesar dos diferentes valores de $\mathrm{P}_{\text {i geral }}$, as médias desses cinco genótipos foram relativamente altas e similares entre si, (Tabela 3). Segundo MENDES et al. (2010), é característica da metodologia LIN \& BINNS (1988) revelar elevada correlação entre altas médias e genótipos com elevada adaptabilidade geral e estabilidade fenotípica, pois associa estabilidade fenotípica aos menores desvios genotípicos, levando em consideração todos os ambientes.

Pela metodologia de CARNEIRO (1998), que classifica os genótipos quanto à adaptabilidade $\mathrm{e}$ estabilidade fenotípica para ambientes favoráveis e desfavoráveis, verificou-se que a testemunha RB867515 também apresentou a maior adaptabilidade e estabilidade fenotípica para ambientes favoráveis (menor $\mathrm{P}_{\text {if }}$ ). Na sequência, destacaram-se os genótipos RB987935, RB925211, RB935641 e RB937570, nessa ordem, respectivamente, ainda que os valores de $\mathrm{P}_{\text {if }}$ desses três últimos sejam consideravelmente maiores em relação aos dos dois primeiros (Tabela 3).

Para ambientes desfavoráveis (menor $\mathrm{P}_{\mathrm{id}}$ ), o genótipo RB935641 revelou ser o mais adaptado e estável fenotipicamente, seguido pelos genótipos RB987935, testemunha RB867515, RB935686 e RB925211, nessa ordem, respectivamente.

Vale destacar que as cinco primeiras posições do ranking de classificação $\mathrm{P}_{\mathrm{i}}\left(\mathrm{P}_{\mathrm{i} \text { geral }}, \mathrm{P}_{\mathrm{if}}\right.$ e $\left.\mathrm{P}_{\mathrm{id}}\right)$ sempre foram ocupadas pelos mesmos genótipos. A 
Tabela 3 - Estimativa do parâmetro de estabilidade fenotípica $\left(\mathrm{P}_{\mathrm{i} \text { geral }}\right)$ de Lin \& Binns e de Carneiro (1998) para ambientes favoráveis ( $\left.\mathrm{P}_{\text {if }}\right)$ e desfavoráveis $\left(\mathrm{P}_{\mathrm{id}}\right)$ para a variável TPH (toneladas de Pol por hectare) de 15 genótipos avaliados em nove ambientes, em Minas Gerais, nas safras 2005 e 2006.

\begin{tabular}{|c|c|c|c|c|c|c|c|}
\hline Genótipos & Médias (t ha ${ }^{-1}$ ) & $P_{i \text { geral }}$ & Posição & $\mathrm{P}_{\text {if }}$ & Posição & $\mathrm{P}_{\text {id }}$ & Posição \\
\hline RB987935 & 20,71 & 1,74 & 2 & 1,65 & 2 & 1,87 & 2 \\
\hline RB867515* & 20,44 & 1,64 & 1 & 1,00 & 1 & 2,43 & 3 \\
\hline RB935641 & 19,81 & 4,53 & 3 & 6,90 & 4 & 1,56 & 1 \\
\hline RB925211 & 19,16 & 5,27 & 4 & 6,57 & 3 & 3,64 & 5 \\
\hline RB935686 & 18,87 & 5,68 & 5 & 7,61 & 6 & 3,28 & 4 \\
\hline RB937570 & 18,65 & 7,17 & 6 & 7,42 & 5 & 6,85 & 8 \\
\hline RB987934 & 18,24 & 9,67 & 7 & 13,69 & 10 & 4,66 & 7 \\
\hline RB956911 & 17,87 & 9,72 & 8 & 14,04 & 11 & 4,32 & 6 \\
\hline RB945065 & 17,62 & 11,00 & 9 & 13,56 & 9 & 7,81 & 9 \\
\hline RB72454* & 17,22 & 12,57 & 10 & 16,13 & 12 & 8,12 & 10 \\
\hline RB957689 & 17,08 & 13,51 & 11 & 13,19 & 7 & 13,90 & 13 \\
\hline RB977625 & 16,88 & 15,89 & 15 & 17,34 & 13 & 14,09 & 14 \\
\hline RB977619 & 16,85 & 14,02 & 12 & 13,28 & 8 & 14,93 & 15 \\
\hline RB987905 & 16,75 & 14,99 & 13 & 17,95 & 14 & 11,29 & 12 \\
\hline RB977508 & 16,75 & 15,17 & 14 & 18,85 & 15 & 10,57 & 11 \\
\hline
\end{tabular}

*Corresponde às cultivares testemunhas.

única exceção foi verificada na classificação do $\mathrm{P}_{\mathrm{if}}$, em que o genótipo RB937570 passou a ocupar a quinta posição e o genótipo RB935686, a sexta. Além de expressar a maior média relativa, o genótipo RB987935 foi o único que se manteve na mesma posição (segunda) nos três rankings $\left(\mathrm{P}_{\mathrm{i} \text { geral, }} \mathrm{P}_{\text {if }}\right.$ e $\left.\mathrm{P}_{\text {id }}\right)$. Dessa forma, esse genótipo pode ser destacado como o mais promissor em relação à produtividade $(\mathrm{TPH})$, adaptabilidade geral e específica para ambientes favoráveis e desfavoráveis.

Em relação aos caracteres agronômicos, o genótipo RB987935 é muito similar à testemunha RB867515 (Tabela 4). Entre os genótipos envolvidos nesse estudo, apenas esses dois apresentam elevadas performances em solos de média a baixa fertilidade, o que é muito importante para as condições de cultivo no estado de Minas Gerais, uma vez que a maioria das áreas cultivadas apresenta baixa fertilidade natural do solo. Além do mais, esse genótipo também apresenta brotação muito boa sob palha, condição a qual fica exposto em decorrência da colheita mecânica, o que é uma característica fundamental para atender à demanda gerada pela evolução tecnológica do setor sucroenergético. É classificado como tolerante ou resistente frente às principais doenças da cultura, tal como o carvão, escaldadura e ferrugem marrom. Em relação ao florescimento, que pode ocorrer eventualmente, esse genótipo apresenta resposta melhor do que a testemunha RB867515 (Tabela 4). Diante dessas considerações, fica evidente o seu elevado potencial para ser liberado como cultivar para cultivo comercial.

Dentre os outros genótipos que apresentaram elevadas médias (TPH $>18 \mathrm{t} \mathrm{ha}^{-1}$ ), destacase, em particular, o genótipo RB925211, que, no presente estudo, ocupou a quarta posição do ranking de adaptabilidade geral e estabilidade fenotípica $\left(\mathrm{P}_{\text {igeral }}\right)$. No estado do Paraná, em um estudo conduzido com 20 genótipos $\mathrm{RB}$, esse mesmo genótipo tem sido destacado como o mais adaptado e estável (ZENI NETO et al., 1998). Nesse mesmo trabalho, os autores também destacaram o genótipo RB956911, que, no presente estudo, ocupou apenas a oitava posição do ranking de classificação da adaptabilidade geral e estabilidade fenotípica $\left(\mathrm{P}_{\mathrm{i} \text { geral }}\right)$. Contudo, deve-se levar em consideração que a série de genótipos avaliados nesse trabalho do Paraná difere dessa do presente estudo. Apesar disso, esse resultado evidencia a importância de se avaliar os genótipos nos mais variados ambientes e, assim, selecionar aqueles que melhor se adaptam a cada condição particular edafoclimática de cultivo.

Ainda que o método de LIN \& BINNS (1988) apresente limitações quanto à obtenção de estimativas de ganhos genéticos para variáveis que envolvam a produtividade, adaptabilidade e estabilidade, por estas não configurarem valores genéticos (BASTOS et al., 2007), esta metodologia ainda tem sido utilizada pelos pesquisadores em função de sua fácil aplicação e eficiência na recomendação de cultivares promissoras para diferentes ambientes (FARIAS et al., 1997; BOTREL et al., 2005; CORREA et al., 2006; MENDES et al., 2010). 
Tabela 4 - Caracterização agronômica dos genótipos de cana-de-açúcar avaliados nas safras de 2005 e 2006 , em Minas Gerais.

\begin{tabular}{|c|c|c|c|c|c|c|c|}
\hline Genótipos & Fertilidade & Brotação & Maturação & Flor & Carvão & Escaldadura & Ferrugem \\
\hline RB72454 & $\mathrm{M}$ & $\mathrm{B}$ & $\mathrm{M} / \mathrm{T}$ & $\mathrm{E}$ & To & I & To \\
\hline RB977508 & M & B & $\mathrm{P} / \mathrm{M}$ & A & $\mathrm{R}$ & $\mathrm{R}$ & $\mathrm{R}$ \\
\hline RB957689 & $\mathrm{H}$ & MB & HP & A & $\mathrm{R}$ & $\mathrm{R}$ & $\mathrm{R}$ \\
\hline RB867515 & $\mathrm{M} / \mathrm{h}$ & MB & $\mathrm{M} / \mathrm{T}$ & A & To & To & $\mathrm{R}$ \\
\hline RB925211 & M & MB & $\mathrm{P} / \mathrm{M}$ & $\mathrm{F}$ & $\mathrm{R}$ & $\mathrm{R}$ & $\mathrm{R}$ \\
\hline RB977619 & M & B & $\mathrm{T}$ & $\mathrm{E}$ & To & To & $\mathrm{R}$ \\
\hline RB935641 & M & MB & $\mathrm{M} / \mathrm{T}$ & $\mathrm{E}$ & To & To & $\mathrm{R}$ \\
\hline RB935686 & M & MB & $\mathrm{M} / \mathrm{T}$ & $\operatorname{Pr}$ & To & To & To \\
\hline RB977625 & $\mathrm{H}$ & B & $\mathrm{T}$ & $\mathrm{E}$ & To & To & To \\
\hline RB937570 & M & B & $\mathrm{P} / \mathrm{M}$ & $\operatorname{Pr}$ & To & To & $\mathrm{R}$ \\
\hline RB945065 & M & B & $\mathrm{T}$ & Pr & I & To & To \\
\hline RB987905 & M & B & $\mathrm{M} / \mathrm{T}$ & $\mathrm{E}$ & To & To & To \\
\hline RB987934 & $\mathrm{H}$ & MB & $\mathrm{T}$ & $\mathrm{E}$ & To & To & $\mathrm{R}$ \\
\hline RB987935 & $\mathrm{M} / \mathrm{h}$ & MB & $\mathrm{M} / \mathrm{T}$ & $\mathrm{E}$ & To & To & $\mathrm{R}$ \\
\hline RB956911 & $\mathrm{M} / \mathrm{H}$ & B & $\mathrm{P} / \mathrm{M}$ & $\mathrm{E}$ & $\mathrm{R}$ & To & I \\
\hline
\end{tabular}

A: ausente, B: boa, E: eventual, F: frequente, H: alta, HP: hiper precoce, h: baixa, I: intermediária, M: média, MB: muito boa, P: precoce, Pr: presente, R: resistente, T: tardia e To: tolerante.

\section{CONCLUSÃO}

Além da adaptabilidade específica para ambientes favoráveis, a testemunha RB867515 apresentou a maior adaptabilidade geral e estabilidade fenotípica. Para ambientes desfavoráveis, o genótipo RB935641 revelou ser o mais adaptado e estável fenotipicamente. O genótipo RB987935 apresentou performance similar à testemunha RB867515 em todos os ambientes de cultivo, sendo, portanto, o genótipo indicado para cultivo comercial.

\section{AGRADECIMENTOS}

Às usinas e destilarias do setor sucroenergético de Minas Gerais pelo suporte financeiro ao Programa de Melhoramento Genético da Cana-de-açúcar (PMGCA-UFV). À Rede Interuniversitária para Desenvolvimento do Setor Sucroalcooleiro (RIDESA), pela concessão dos clones usados na pesquisa e, ao Conselho Nacional de Desenvolvimento Científico e Tecnológico (CNPq), Financiadora de Estudos e Projetos (FINEP) e Fundação de Amparo à Pesquisa do Estado de Minas Gerais (FAPEMIG), pelas bolsas de estudo concedidas aos estudantes.

\section{REFERÊNCIAS}

BARROS, H.B. et al. Análises paramétricas e não-paramétricas para determinação da adaptabilidade e estabilidade de genótipos de soja. Scientia Agraria, v.9, p.299-309, 2008. Disponível em: $<$ http://redalyc.uaemex.mx/redalyc/pdf/995/99516777005.pdf $>$. Acesso em: 20 jul. 2011.

BASTOS, I.T. et al. Avaliação da interação genótipo x ambiente em cana-de-açúcar via modelos mistos. Pesquisa Agropecuária Tropical, v.37, p.195-203, 2007. Disponível em: <http://www.revistas.ufg.br/index.php/pat/article/download/ 3077/3116>. Acesso em: 20 jul. 2011.

BOTREL, M.A. et al. Adaptabilidade e estabilidade de cultivares de alfafa avaliadas em Minas Gerais. Ciência e Agrotecnologia, v.29, p.409-414, 2005. Disponível em: $<$ http://www.scielo.br/pdf/cagro/v29n2/a19.pdf>. Acesso em: 20 jul. 2011. doi: 10.1590/S1413-70542005000200019.

CARNEIRO, P.C.S. Novas metodologias de análise da adaptabilidade e estabilidade de comportamento. 1998. 168f. Tese (Doutorado em Genética e Melhoramento) Universidade Federal de Viçosa, Viçosa, MG.

CONAB. Companhia nacional de abastecimento. Central de informações agropecuárias: safras - cana (2011). Disponível em: <http://www.conab.gov.br>. Acesso em: 20 maio, 2011.

CORREA, L.V.T. et al. Comportamento de progênies de cafeeiro Icatu. Ciência e Agrotecnologia, v.30, p.618-622, 2006. Disponível em: <http://www.scielo.br/pdf/cagro/v30n4/ v30n4a04.pdf>. Acesso em: 20 jul. 2011. doi: 10.1590/S141370542006000400004 .

CRUZ, C.D. Programa genes: biometria. Viçosa: UFV, 2006. 382p.

CRUZ, C.D.; CARNEIRO, P.C.S. Modelos biométricos aplicados ao melhoramento genético. Viçosa: UFV, 2006. $585 p$.

CRUZ, C.D. et al. Modelos biométricos aplicados ao melhoramento genético. Viçosa: UFV, 2004. 480p.

DAHER, R.F. et al. Estabilidade da produção forrageira em clones de capim-elefante (Pennisetum purpureum Schum.). Ciência Agrotecnologia, v.27, p.788-797, 2003. Disponível em: <http://www.scielo.br/pdf/cagro/v27n4/v27n4a07.pdf>. Acesso em: 20 jul. 2011. doi:10.1590/S141370542003000400007 . 
DIOLA, V.; SANTOS, F. Fisiologia. In: SANTOS, F. et al. (Eds.). Cana-de-açúcar: bioenergia, açúcar e álcool Tecnologias e perspectivas. Viçosa: UFV, 2010. p.25-49.

FARIAS, F.J.C. et al. Parâmetros de estabilidade propostos por LIN \& BINNS (1988) comparados com o método da regressão. Pesquisa Agropecuária Brasileira, v.32, p.407-414, 1997. Disponível em:<http://webnotes.sct.embrapa.br/pab/pab.nsf/ FrAnual>. Acesso em: 20 jul. 2011.

GOMES, F.P. Curso de estatística experimental. Piracicaba: USP, 2000. 477p.

GUERRA, E.P. et al. Stability and adaptability of early maturing sugarcane clones by AMMI analysis. Crop Breeding and Applied Biotechnology, v.9, p.260-267, 2009. Disponível em: <http://www.sbmp.org.br/cbab/siscbab/uploads/c8eb97910994-c5a5.pdf>. Acesso em: 20 jul. 2011

LAVORENTI, N.A.; MATSUOKA, S. Combinação de métodos paramétricos e não-paramétricos na análise de estabilidade de cultivares de cana-de-açúcar. Pesquisa Agropecuária Brasileira, v.36, p.653-658, 2001. Disponível em: <http:// www.scielo.br/pdf/pab/v36n4/5147.pdf >. Acesso em: 20 jul. 2011. doi: 10.1590/S0100-204X2001000400008.
LIN, C.S.; BINNS, M.R. A method of analyzing cultivars $x$ location $\mathrm{x}$ year experiments: new stability parameter. Theoretical Applied Genetics, v.76, p.425-430, 1988. Disponível em: <http://www.springerlink.com/content/ h3504x6x04526t5x/fulltext.pdf>. Acesso em: 20 jul. 2011. doi: 10.1007/BF00265344

MENDES, T.O.P. et al. Pi statistics underlying the evaluation of stability, adaptability and relation between the genetic structure and homeostasis in popcorn. Acta Scientiarum, v.32, p.269-277, 2010. Disponível em: <http:// periodicos.uem.br/ojs/index.php/ActaSciAgron/article/view/ 7312/7312>. Acesso em: 20 jul. 2011. doi: 10.4025/ actasciagron.v32i2.7312.

MURAKAMI, D.M. et al. Considerações sobre duas metodologias de análise de estabilidade e adaptabilidade. Ciência Rural, v.34, p.71-78, 2004. Disponível em: <http:// www.scielo.br/pdf/cr/v34n1/a11v34n1.pdf $>$. Acesso em: 20 jul. 2011. doi: 10.1590/S0103-84782004000100011.

NASCIMENTO FILHO, F.J. et al. Adaptabilidade e estabilidade de clones de guaraná. Pesquisa Agropecuária Brasileira, v.44, p.1138-1144, 2009. Disponível em: <http://www.scielo.br/ pdf/pab/v44n9/v44n9a11.pdf>. Acesso em: 20 jul. 2011. doi: 10.1590/S0100-204X2009000900011. 